\title{
Primary and Comprehensive Stroke Centers: History, Value and Certification Criteria
}

\author{
Philip B. Gorelick ${ }^{\mathrm{a}, \mathrm{b}}$ \\ ${ }^{a}$ Translational Science and Molecular Medicine, Michigan State College of Human Medicine, Michigan, USA \\ bHauenstein Neuroscience Center, Saint Mary's Health Care, Michigan, USA
}

In the United States (US) stroke care has undergone a remarkable transformation in the past decades at several levels. At the clinical level, randomized trials have paved the way for many new stroke preventives, and recently, several new mechanical clot retrieval devices for acute stroke treatment have been cleared for use in practice by the US Federal Drug Administration. Furthermore, in the mid 1990s we witnessed regulatory approval of intravenous recombinant tissue plasminogen activator for administration in acute ischemic stroke. In the domain of organization of medical care and delivery of health services, stroke has transitioned from a disease dominated by neurologic consultation services only to one managed by vascular neurologists in geographical stroke units, stroke teams and care pathways, primary stroke center certification according to The Joint Commission, and most recently comprehensive stroke center designation under the aegis of The Joint Commission. Many organizations in the US have been involved to enhance stroke care. To name a few, the American Heart Association/American Stroke Association, Brain Attack Coalition, and National Stroke Association have been on the forefront of this movement. Additionally, governmental initiatives by the US Centers for Disease Control and Prevention and legislative initiatives such as the Paul Coverdell National Acute Stroke Registry program have paved the way to focus on stroke prevention, acute treatment and quality improvement. In this invited review, we discuss a brief history of organized stroke care in the United States, evidence to support the value of primary and comprehensive stroke centers, and the certification criteria and process to become a primary or comprehensive stroke center.

Keywords: Comprehensive stroke center; Primary stroke center; Organization of health care

\author{
Correspondence: Philip B. Gorelick \\ Translational Science and Molecular \\ Medicine, Michigan State College of \\ Human Medicine and Hauenstein \\ Neuroscience Center, Saint Mary's \\ Health Care, 220 Cherry Street SE \\ Grand Rapids, Michigan 49503, \\ USA \\ Tel: +616-685-6455 \\ Fax: +616-685-4351 \\ E-mail: pgorelic@trinity-health.org
}

Received: December 29, 2012

Revised: January 24, 2013

Accepted: January 24, 2013

The author have no financial conflicts of interest.

\section{Introduction}

Evidence that organization of cardiovascular care may be effective in reduction of morbidity and mortality has existed since at least the 1950s when cardiologists implemented specialized care in coronary units for patients with acute heart disease. ${ }^{1} \mathrm{We}$ learned in chemistry class of the laws that govern free energy that positive entropy, a low or 'disordered' energy state, can be righted by pumping energy into such a system. ${ }^{2}$ Similarly, it stands to reason that in stroke care, an organized structure can be developed by placing appropriate resources, management and vision into the system and by supplying the 'energy' (i.e., enthusiastic stroke team members) to make the system function well. ${ }^{2}$ Furthermore, it has been shown multiple times that organized stroke care in the form of stroke care units reduces morbidity and mortality associated with stroke. ${ }^{1}$ Components and processes associated with stroke units have included but are not limited to stroke care maps, stroke teams, and quality im- 
provement efforts. ${ }^{2}$ In some regions such as in North America, primary stroke centers have become the key unit of organization for the delivery of stroke care, and more recently comprehensive stroke center certification has become a reality under the regulatory guidance of the The Joint Commission. The Joint Commission sets quality standards for hospitals in the United States and serves as a certifying body for hospitals and for certain hospital-based programs such as in stroke. Comprehensive stroke centers provide a structure to take stroke care to a new level of excellence, the potential for handling more complicated stroke cases and a venue to provide better outcomes.

In this review we discuss a brief history of organized stroke care in the United States, evidence to support the value that primary and comprehensive stroke centers may bring, and the criteria and certification process to become a primary or comprehensive stroke center. We have entered a new era or stroke care that is being ushered in by comprehensive stroke centers and new advances in stroke prevention, diagnosis and treatment. ${ }^{3}$

\section{Brief History of Organized Stroke Care in the United States}

Healthy People 2010 and Paul Coverdell National Acute Stroke Registry. Now, we embark on a discussion of the history of organized stroke care in the United States (US) in the modern era. In the US organization of stroke care was heightened by two key national prevention initiatives that were brought about by the need to address almost 900,000 stroke-related hospitalizations annually, over $\$ 50$ billion in lost productivity and health care costs, and the personal ravages of physical and psychosocial devastation associated with stroke. ${ }^{4}$ The initiatives were sponsored by the United States Center for Disease Control and Prevention and were designed to improve stroke health. They included Healthy People 2010 and the Paul Coverdell Stroke Registry. The former initiative was developed to identify substantial preventative health threats to US citizens, increase the quality and years of life, and eliminate health disparities. ${ }^{4}$ Sixteen of a total of 467 objectives were established to address heart disease and stroke. The Paul Coverdell National Acute Stroke Registry program was implemented in 2001 as state-based stroke quality registries to measure and follow acute stroke care outcomes, and lead to high quality acute stroke care and prevention of stroke mortality and recurrence. Wave I (2001) of the Paul Coverdell National Acute Stroke Registry program included 4 states and Wave II (2002) included 5 states. Then, in June 2004, funds were provided at the state level for Coverdell registries in Georgia, Illinois, Massachusetts and North Carolina earmarked to develop and implement programs for data collection and analysis for quality improvement interventions at the hospital level catalyzed by partnerships with physicians, stroke care teams, and hospital administrators. ${ }^{4}$ Finally, in 2007 funding was provided to 6 state health departments for continued quality improvement work in acute stroke, and the registry remains active.

In the US in the late 1990s and early 2000s there was an obvious need for quality improvement in acute and recurrent stroke preventive care. It was suspected that application of quality stroke care was unevenly distributed. For example, we carried out a statewide assessment of acute stroke diagnostic and treatment capabilities in the Midwestern State of Illinois among 183 of 202 (91\%) adult acute care inpatient medical hospital facilities between December 1999 and June 2000. ${ }^{5}$ Key select findings from our survey are listed in Table 1. As can be observed in Table 1 , significant gaps in acute stroke care existed primarily in the non-Greater Chicago Metropolitan Area though both the non- Greater Chicago Metropolitan Area and Greater Chicago Metropolitan Area had key gaps in stroke community awareness programs and availability of acute stroke care teams. ${ }^{5}$ In a survey in North Carolina conducted before our survey and from which our survey was patterned, there were gaps found in availability of acute stroke care teams, stroke care maps, stroke units, and rapid patient identification programs. ${ }^{6}$ Around the year 2000 these surveys demonstrated the need for improvement in acute stroke care, and therefore, the need for stroke quality initiatives such as the Coverdell program to catalyze quality stroke care and raise awareness of such need. In a follow-up study by Goldstein in North Carolina, the availability of certain diagnostic tests, but not specialty staff or stroke units, increased between 1998 and 2008, and there were possible improvements between 2003 and 2008, suggesting possible establishment of programs

Table 1. Key Findings from a Statewide Assessment of Acute Stroke Care Diagnostic and Treatment Facilities in Illinois ${ }^{5}$

Emergency Department Receiving Facility: 99\%

Cranial Computed Tomography Scanner: 98.3\%

rtPA Treatment Protocol for Acute Ischemic Stroke: slightly > 70\%

Residents Living in a County with at Least 1 Acute Care Facility with a rtPA Treatment Protocol: 93.2\%

Treatment Capabilities Lacking in Non-Greater Chicago Metropolitan Area: neurologist, neurosurgeon, transcranial Doppler, Diffusion-Weighted magnetic resonance imaging (MRI), and MR Angiography

Programmatic Aspects Lacking in both Non- Greater Chicago Metropolitan Area and Greater Chicago Metropolitan Area: stroke community awareness programs and acute stroke care teams 
to develop stroke care systems. ${ }^{7}$

Emergency Medical Services, Stroke Center Network, and Brain Attack Coalition. After the approval of recombinant tissue plasminogen activator (rtPA) therapy for treatment of acute ischemic stroke in the mid-1990s, there was a need for integration and organization of Emergency Medical Services (EMS) as part of an effective stroke system. Such organizations in the United States as the American Heart Association/American Stroke Association (AHA/ASA) and the National Stroke Association (NSA) supported an integrated and organized approach to EMS involvement and the use of "911" telephone triggers to prompt EMS to respond to stroke as a high level emergency ${ }^{8}$ and follow the principles of rapid identification and treatment of acute stroke. ${ }^{9}$ Furthermore, in the mid-1990s the NSA Stroke Center Network program was developed, and NSA established the NSA Stroke Center Recommendation Guidelines which were used to develop a foundation for stroke center infrastructure. ${ }^{4,10}$ The latter were incorporated by the Brain Attack Coalition (BAC), formed in 1996, to improve medical services and detection of stroke. ${ }^{4,11}$ The BAC has been instrumental in helping to craft guidelines for primary and comprehensive stroke center programs as we will discuss in a section below.

The three aforementioned organizations are independent of one another. AHA/ASA is an organization dedicated to advocacy and education of the public and health care providers for prevention, treatment, diagnosis and rehabilitation of heart attack and stroke and for funding of scientific endeavors in the respective disease-specific areas. NSA has a major goal of patient advocacy in stroke and is also dedicated to education of patients and health care providers for stroke prevention, treatment, diagnosis and rehabilitation. $\mathrm{BAC}$ has been involved in making recommendations for stroke prevention and treatment and for holding educational meetings for physician providers and clinical researchers in the stroke field.

Primary Stroke Center Certification. In 2003 the AHA/ASA and The Joint Commission agreed on a certification process for stroke through a Disease-Specific Certification program that included a voluntary evaluation process driven by the demonstration of a consistent approach to clinical outcome measurement and minimum standards for stroke care built around acute ischemic stroke treatment with rtPA. ${ }^{4}$ Primary Stroke Center Certification began in 2004 and by April 2005 about 15 hospitals per month were being reviewed. ${ }^{4}$ By 2011, there were over 800 The Joint Commission primary stroke centers in the US out of some 4000-5000 total hospital facilities. Some states in the United States have established a state designation for stroke centers through a local health department certification mechanism, and in some regions legislation has been passed to have acute stroke patients bypass non-primary stroke center designated hospitals to allow diagnosis and treatment at primary stroke center-designated acute receiving hospitals.

It is acknowledged that quality initiatives for stroke care have evolved throughout the world and that Joint Commission International developed a process for certifying hospitals outside of the US. ${ }^{4}$ Whereas in the US a major focus has been the primary stroke center as the unit for acute stroke treatment, facilities in European hospitals for treating stroke patients have focused on the stroke unit as the primary organizational component for acute stroke care. In 2005, a survey of 886 randomly selected hospitals in 25 countries showed that less than $10 \%$ of European hospitals treating acute stroke patients had optimal facilities, and in about $40 \%$ the minimal standard was not met. ${ }^{12}$

Mississippi Stroke Education Consortium and Regional Care. Finally, one of the first larger scale systematic approaches to regional stroke care in the US was the Mississippi Stroke Education Consortium, guided by a state-based volunteer advocacy group that was founded in 1994 to set policy to decrease the impact of stroke through an ongoing educational process geared to laypersons and healthcare professionals. ${ }^{13}$ Among many advances the Mississippi Stroke Education Consortium provided a proposal for the development of a statewide emergency stroke network that included the following 5 components: 1) A substantial initial education template for health care professionals and the public; 2) Acute and subacute stroke care criteria; 3) Level I-III medical center designation according to ability to meet acute and subacute care criteria; 4) EMS transport criteria; and 5) A continuous education plan for public and health care providers.

Growth of regional stroke care in the first decade of the 21st century has been substantial. In 2000, the first counties adopted regional regulations to route acute stroke patients to primary stroke centers, and this was followed by adoption of such policies in 2 states in 2004. ${ }^{14}$ By 2010, 16 states and counties in 3 additional states had such legislation for EMS to route acute stroke patients to primary stroke centers and bypass those noncertified facilities. By the end of 2010, it was estimated that 53\% of the US population was covered by such routing protocols. ${ }^{14}$

\section{Evidence to Support the Value of Primary Stroke Centers}

Scope of Review and Get With The Guidelines-Stroke. Carrying out an original systematic review and meta-analysis of the evidence supporting the value of primary stroke centers is beyond the scope of this review. Therefore, we will limit our discussion to select studies known to the author. An important aspect of organization of quality stroke care is the availability of a 
database solution to track outcomes and make improvements to care based on ongoing data analysis and checks. ${ }^{15}$ The AHA/ ASA Get With The Guidelines-Stroke (GWTG-S) program provides such a data solution and has been utilized by over 1,000 hospitals in the US and has over 1 million patient records. GWTG-S serves as a national stroke registry and quality improvement program and is believed to be representative of the national fee-for-service Medicare ischemic stroke population. ${ }^{16}$ In a recent review of metric compliance and improved patientcentered outcomes in stroke, it was concluded that there are limited high-quality studies and methodologic flaws exist making it difficult to interpret the reported associations. ${ }^{17}$ Furthermore, the possible importance of residual confounding in the study of hospitalized stroke patients in relation to the influence of compliance with guideline-based processes on risk-adjusted mortality and adjustment for stroke severity have been emphasized. $^{18,19}$

Examples of Need for Better Organization of Stroke Care. There are a number of examples that demonstrate the need for better organization of stroke care that can be anchored by primary stroke centers. For example, in 2001 Burgin et al. reported that whereas a high percentage of acute stroke patients received computed tomography brain studies in non-urban East Texas communities, aggressive treatment of blood pressure commonly occurred and at blood pressures below treatment recommendations. ${ }^{20}$ Rural areas and small communities in the US and elsewhere have been the subject of health disparities in stroke care and the need to have an appropriate nexus to implement best-practice recommendations. ${ }^{21,22}$ Furthermore, despite national stroke public awareness campaigns, public knowledge of strokerisk factors and warning signs has not improved substantially over time, and care seeking after stroke symptoms remains suboptimal ( $\sim 50 \%$ of cases) ${ }^{23,24}$ In addition, there is potential for a large financial cost associated with inadequate primary and recurrent stroke prevention measures, and rehospitalizations among Medicare beneficiaries has become a target for financial penalties leveled on hospitals by the US Center for Medicare and Medicaid Services. ${ }^{25,26}$ Provision of recurrent stroke prevention services has been shown to be suboptimal in a high percentage of stroke patients and thus, provides further justification for the need to improve upon the delivery of such services. ${ }^{27}$ Also, there is a need for better transitioning of stroke patients from the inpatient hospital or rehabilitation setting to home or institutional care. ${ }^{28}$ In-hospital initiation of stroke prevention and allied therapies may serve as a means to improve such transitioning. ${ }^{29}$ Better organizational systems such as those provided by well-constructed primary stroke center models are needed to accomplish this.
Added Value and Feasibility. Finally, organized stroke care adds value in that it reduces the following risks associated with stroke: death by $14 \%$, death or institutionalized care by $18 \%$, and death or dependency by $18 \%{ }^{30-33}$ Importantly, in the US it has been shown that the possibility of establishing a primary stroke center is both desirable and reachable as the presence of resources needed to achieve primary stroke center status is present in an estimated over $40 \%$ of US hospitals.

Additional Rationale. There is additional rationale to justify organization of stroke care according to primary stroke center or stroke unit processes. Safety of hospital care has become a major target for improvement. Adverse events and errors may be common in stroke patients. In a 750-bed academic hospital during a 3.5 year period ending in 2004, 173 (12.0\%) patients had an adverse event. Common events as might be expected in stroke patients included falls, medication errors, and adverse events. ${ }^{34}$ According to the study findings, it was estimated that almost $50 \%$ of the adverse events were preventable and involved medications and other situations commonly occurring in care delivery processes in a stroke patient group and ranged from acute thrombolytic administration to end-of-life care. Of the preventable adverse events $37 \%$ were transcription/documentation errors, $23 \%$ a failure to perform a clinical task, $10 \%$ were communication or handoff errors, and $10 \%$ were failure to perform independent checks or proper calculations. Organizational means to solve such gaps in care such as primary stroke center or stroke unit systems are available. Implementation of stroke unit care, for example, has been available for decades and has been shown to reduce risk of death via the prevention of treatment complications. ${ }^{35,36}$ In addition, database solutions such as GWTG-S are now used to help identify certain process gaps in stroke care in need of resolution.

Stroke Center Designa tion and Quality Improvement. Stroke center designation has been associated with a number of quality improvements including but not limited to access to timely thrombolytic therapy and utilization of stroke unit care. ${ }^{37}$ Primary stroke centers may be established successfully as a metropolitan-wide matrix in large population areas to facilitate diagnosis and treatment of acute stroke patients. ${ }^{38}$ Organization of acute stroke in this way may be advantageous especially when there is high annual hospital volume or high physician patient volume in relation to stroke care which heightens preferable outcomes or cost savings. ${ }^{39,40}$ An organized stroke care system such as an inpatient stroke unit has been associated with reduced length of care and case fatality, cost-effectiveness when followed by early supportive discharge, and as a model for stroke care, generalizeability if implemented in non-principal referral hospitals. ${ }^{41-43}$ It should be noted that there is evidence to sug- 
gest that primary stroke center designated hospitals had better outcomes than non-certified hospitals before The Joint Commission (TJC) program for primary stroke center designation was implemented. Possibly, the certified hospitals had organizational programs already in place prior to achieving certification status.

Who Should Be Leading Stroke Team Management? There has been debate as to whether a specifically-trained vascular neurologist or other physician should manage stroke patients from the time of onset of stroke and beyond. ${ }^{446}$ It has been argued that vascular neurologists and others trained specifically to treat stroke patients have better stroke outcomes but may be associated with higher costs of stroke care. Caplan has opined that among all of the physicians who could be involved in stroke care, neurologists with interest, training and experience in caring for stroke patients are most likely to have the proper attributes to manage stroke patients. ${ }^{44}$ Lees acknowledges the need for more stroke specialists. ${ }^{45}$ The consensus, therefore, is that those trained to take care of stroke patients are best suited to provide stroke care. ${ }^{46}$ It has been shown that: 1) The higher the level of stroke care organization and complexity of stroke case mix, in general the better the patient outcomes; ${ }^{47} 2$ ) The higher the level of organized stroke care, the lower the 30-day mortality for each ischemic stroke subtype ${ }^{48}$; and 3 ) With organized acute stroke care, all age groups may benefit as there is reduced institutionalization or death. ${ }^{49}$ Therefore, the role of the stroke team lead physician and the overall system of organization for stroke care are highly inter-related and important aspects of the care delivery system.

Role and Value of Stroke Performance Measures. The implementation of stroke performance measures has been associated with large-scale improvement in stroke care. ${ }^{50}$ Stroke performance measures primarily have emphasized acute and subacute aspects of stroke care, and thus, there is a need to expand the measures to be more inconclusive of outpatient stroke care and functional recovery. When the influence of patient and hospital factors are taken into account, in the Paul Coverdell National Acute Stroke Registry, hospital-level factors explained about $18 \%$ of total variation in quality of care, whereas the majority of variability in quality stroke care was accounted for by patientlevel factors $(82 \%) .^{51}$

Major criteria for the establishment of primary stroke center membership have been associated with benefits in acute stroke treatment processes. For example, among 34 academic medical centers, institutions that follow a greater number of BAC features were more likely to administer rtPA..$^{52}$ In addition, in the California Acute Stroke Pilot Registry, a Coverdell pilot registry, implementation of standardized stroke orders and monitor- ing was associated with improvement in use of proven acute stroke treatment or prevention interventions. ${ }^{53}$ Furthermore, the impact of standardized stroke orders at discharge were studied in a cluster-randomized trial by the Quality Improvement in Stroke Prevention investigators in 12 hospitals. ${ }^{54}$ The primary outcome was optimal treatment at 6 months defined as taking a statin agent, blood pressure $<140 / 90 \mathrm{~mm} \mathrm{Hg}$, and receipt of anticoagulation if atrial fibrillation was present. With the hospital as the unit of analysis, the endpoint, optimal treatment, was not significant, whereas at the individual patient level rates of optimal treatment did improve in the intervention compared to non-intervention hospitals. Two other randomized trials, hohowever, failed to show benefit of performance feedback on ischemic stroke care quality markers after discharge. ${ }^{55,56}$

Contributions of GWTG-S. As previously mentioned, GWTG-S has provided a substantial amount of guidance in relation to quality of care and outcomes in acute stroke in the US and elsewhere. In Asia, for example, it has been shown that GWTG$S$ performance measures are applicable with appropriate modification for ethnic factors. ${ }^{57}$ In the US there have been a series of important publications from GWTG-S. Now, we review select papers from GWTG-S and in Table 2 provide a summary of key findings.

Based on 905 hospitals and 479,284 consecutive stroke or TIA admissions, the influence of stroke subtype on quality of care was reported. ${ }^{58}$ There were $61.7 \%$ ischemic strokes, $23.8 \%$ TIAs, $11.1 \%$ intracerebral hemorrhages, and 3.5\% subarachnoid hemorrhages. Overall, many hospital-based acute stroke care and prevention measures were underutilized in intracerebral hemorrhage and subarachnoiod hemorrhage when compared to ischemic stroke/TIA. ${ }^{58}$ The time period of study spanned from April 1, 2003 to December 30, 2007.

Based on 322,847 hospitalized stroke patient discharges from a volunteer sample of 790 US academic and community hospitals during the time period 2003-2007, participation in GWTG$S$ was analyzed to determine if there were improvements in performance adherence. ${ }^{59}$ Compared to baseline, by the 5 th year, the following improvements were noted in 7 performance measures: administration of intravenous thrombolytics ( $42 \%$ vs. $73 \%$ ), early antithrombotics (91\% vs. $97 \%$ ), deep venous thrombosis prophylaxis ( $74 \%$ vs. $90 \%$ ), discharge antithrombotics ( $96 \%$ vs. $99 \%$ ), anticoagulation for atrial fibrillation (95\% vs. $98 \%$ ), lipid treatment ( $74 \%$ vs. $88 \%$ ), and smoking cessation ( $65 \%$ vs. $94 \%$ ), and the composite of performance measures (84\% vs. $94 \%$ ) with $P<0.0001$ for all comparisons. ${ }^{59}$ Furthermore, there was a 1.18-fold yearly increase in the odds that care opportunities were independent of secular trends, and improved stroke care was observed in all hospitals no matter of size, geog- 
Table 2. Select Findings on Quality of Stroke Care and Stroke Outcomes in Get With The Guidelines-Stroke ${ }^{58-64}$

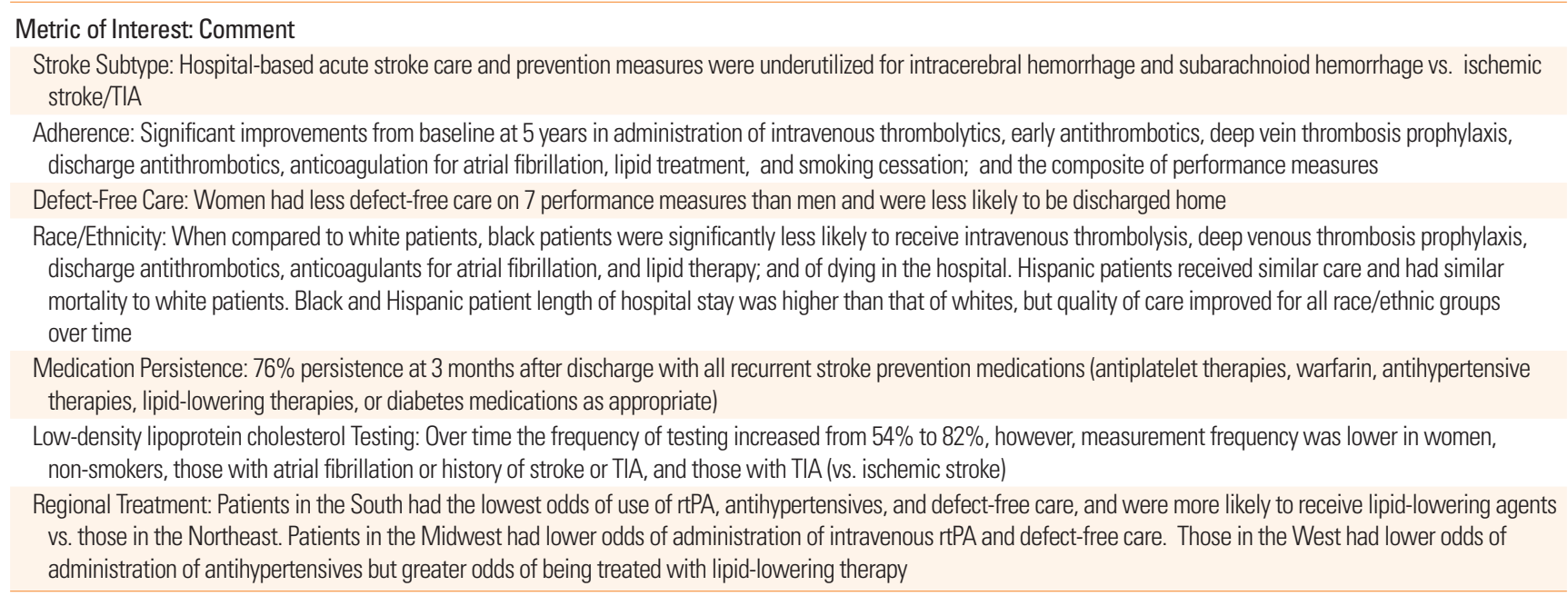

raphy and teaching status.

Based on 383,318 acute ischemic stroke admissions from 1,139 hospitals between 2003 and 2008, 7 performance measures (see above paragraph for performance measures) were assessed for defect-free care between women and men. ${ }^{60}$ Overall, women had less defect-free care than men (66\% vs. $71 \%$ ) and were less likely to be discharged home ( $41 \%$ vs. $50 \%)$. The authors suggested that the differences may be due to residual confounding or other unmeasured factors but that additional research was needed to determine reasons for the health care disparities. $^{60}$

Based on 397,257 patients with ischemic stroke from 1,181 hospitals during the time period between 2003 and 2008, 7 performance measures were studied to determine differences in care according to race/ethnicity. ${ }^{61}$ Overall, when compared to white patients, black patients were significantly less likely to receive intravenous thrombolysis, deep venous thrombosis prophylaxis, discharge antithrombotics, anticoagulants for atrial fibrillation, and lipid therapy, and of dying in the hospital. Hispanic patients received similar care and had similar mortality to white patients. Black and Hispanic patient length of hospital stay was higher than that of whites, but quality of care improved for each race/ethnic groups over time. ${ }^{61}$

Based on 2,598 patients with ischemic stroke or TIA in 106 hospitals followed from discharge to 3 months, $76 \%$ at 3 months were taking all recurrent stroke prevention medications (antiplatelet therapies, warfarin, antihypertensive therapies, lipidlowering therapies, or diabetes medications as appropriate) administered at discharge. ${ }^{62}$ Persistence was associated with decreasing number of classes of medications prescribed, increasing age, medical history, less severe stroke disability, having insurance, working status, health literacy, increasing quality of life, financial hardship, geographic region and hospital size.

Based on 479,284 consecutive ischemic stroke or TIA admissions from 981 hospitals during the time period 2003-2008, the frequency of low-density lipoprotein cholesterol testing was determined. Over time the frequency of testing increased from $54 \%$ to $82 \%$, however, measurement frequency was lower in women, non-smokers, those with atrial fibrillation or history of stroke or TIA, and those with TIA (vs. ischemic stroke) ${ }^{63}$ Furthermore, low-density lipoprotein cholesterol testing was higher the longer a program participated in GWTG.

Based on 991,995 admissions from 4 US regions during the time period 2003-2010, 8 guideline recommended treatments including intravenous rtPA, antihypertensives at discharge, smoking cessation counseling, weight loss education, antithrombotics, anticoagulants for atrial fibrillation, deep venous thrombosis prophylaxis, and lipid-lowering medications at discharge were studied..$^{64}$ Overall, use of each of the therapies varied according to the following results: $58-68 \%$ for intravenous $\mathrm{rtPA}, 73-76 \%$ for lipid-lowering therapy, 80-84\% for antihypertensives, 96 97\% for antithrombotics, $88-91 \%$ for deep venous thrombosis prophylaxis, $49-55 \%$ for weight loss reduction, and $72-77 \%$ for defect-free care. By region, patients in the South had the lowest odds of use of rtPA, antihypertensives, and defect-free care, but were more likely to receive lipid-lowering agents vs. those in the Northeast. Patients in the Midwest had lower odds of administration of intravenous rtPA and defect free care. Those in the West had lower odds of administration of antihypertensives but greater odds of being treated with lipid-lowering therapy.

Role and Value of Telestroke. It is estimated that approximately $50 \%$ of the US population has reasonable access to a primary stroke center. ${ }^{65}$ For those that do not have timely access to a primary stroke center, some may benefit from access to a center 
with telemedicine through a hub-spoke relationship between a hospital without stroke expertise and one with telestroke expertise. In a recent survey to determine active telemedicine programs for stroke in the US, 56 such programs had confirmed telestroke activity including 38 programs from 27 states. ${ }^{66}$ Whereas these programs are thriving in certain regions, some such activities may be challenged by lack of reimbursement for services, lack of program funds, inability to obtain physician licensure, and other challenges. ${ }^{66}$ Evidence and policy statements by AHA/ASA have been published previously to help position telestroke activities ${ }^{67,68}$ as have a practical aspects of telestroke systems' guide. ${ }^{69}$

Telestroke is a means to extend stroke expertise to underserved areas and when applied by competent individuals, it is a viable remote presence alternative option to in-person availability, increases delivery of rtPA in acute ischemic stroke, and can do so within acceptable standard rates of efficacy and safety. ${ }^{70-74}$

Cost and Cost-Effectiveness. The cost of stroke in the US and cost analysis of stroke centers, telestroke and rtPA administration have been reviewed previously by Demaerschalk and colleagues. ${ }^{75,76}$ It has been argued that because stroke centers can reduce length of hospital stay and both stroke centers and telemedicine programs can increase the use of rtPA, it is very possible that these care processes are cost-effective. ${ }^{75-78}$ In the original BAC publication on recommendations for the establishment of primary stroke centers, a similar argument was made that costs might be recouped by shortening length of stay for hospitalized stroke patients and by reducing complications associated with stroke. ${ }^{79}$ Length of hospital stay is considered one of the major drivers of costs associated with stroke and other inpatient medical care. ${ }^{80}$ Reduction of length of hospital stay and rehospitalizations has heightened importance based on the new US healthcare system plan for reimbursement and cost savings. Additional high-quality cost-effectiveness research in relation to stroke center and telemedicine is needed to guide judicious future use of health care resources. ${ }^{76}$

\section{Evidence to Support the Value of Comprehensive Stroke Centers}

Thus far, we have shown that organized stroke care in the form of enhanced medical delivery processes such as stroke units and primary stroke centers is associated with improvements in a number of performance measures, may be associated with reduced mortality and dependency, and other benefits. Emphasis on reducing medical errors and prevention of early rehospitalizations has become a major focus in the US healthcare system, and thus, highlights the need for systems of care that will reduce medical errors and complications. Given the potential for a high complexity of stroke case mix and the need to deliver cuttingedge interventions, a movement to establish comprehensive stroke centers has evolved. Comprehensive stroke centers are those capable of handling a full spectrum of care to seriously ill patients with stroke and cerebrovascular disease. ${ }^{81}$

Since there has been a relative paucity of study, there is limited information about scientific evidence to support the value of comprehensive stroke centers. The argument strongly in favor of comprehensive stroke centers is based on the need for a higher level of specialized care given the spectrum of available diagnostic, treatment, preventive and rehabilitation resources, and new technical advents in these respective areas. Several studies have emerged that support the value of comprehensive stroke centers. For example, there may be a disparity between outcomes for stroke patients admitted to hospitals during weekends vs. weekdays. In one study comprehensive stroke centers showed no difference in 90-day mortality for stroke patients admitted on weekends vs. weekdays, whereas the risk of death if admitted on weekends at other care facilities was higher on weekends. ${ }^{82}$ Furthermore, in a registry-linkage system study from Finland, the number-needed-to-treat to prevent 1 death or institutional care at 1 year was 29 for comprehensive stroke centers vs. 40 for primary stroke centers when compared to general hospitals. ${ }^{83}$ A British study showed that stroke interventional endovascular services were available in only a small number of hospitals, and only about $50 \%$ of them who had no available endovascular service for stroke had transfer plans with a center that did provide the services. ${ }^{84}$

\section{Certification Process for Primary and Comprehensive Stroke Centers}

Primary Stroke Centers. An important step moving forward for the establishment of primary stroke center certification was the $\mathrm{BAC}$ recommendations for primary stroke centers. ${ }^{79}$ Major elements of a primary stroke center according to BAC included: 1) Patient care areas (e.g., acute stroke teams, written care protocols, emergency medical services, emergency department services, a stroke unit for those centers providing ongoing inpatient care for stroke patients, and neurosurgical services); 2) Support services (commitment from the parent medical organization, a stroke center director, neuroimaging services, laboratory services, outcome and quality improvement activities, and continuing medical education).$^{79} \mathrm{~A}$ key message of the BAC recommendations was timely provision of acute stroke services, and therefore, such laboratory services as general ones, electrocardiography and chest X-ray needed to be available on a 24hour/day, 7-day/week basis; computed tomography brain scanning on a 24-hour/day, 7-day/week basis; and neurosurgical 
services within 2 hours. ${ }^{4,15}$

With the establishment of primary stroke center recommendations, the next step was the development of a process for certification. As previously mentioned in this review, TJC and AHA/ASA agreed on a certification process for stroke that was classified as a Disease-Specific Certification. ${ }^{4}$ Three major elements of TJC Primary Stroke Center Certification were established: 1) Compliance with and use of evidence-based stroke guidelines; 2) Implementation of TJC standards (e.g., accuracy of patient identification, effectiveness of communication among caregivers, reconciliation of medications, reduction of risk of harm from falls, and TJC disease-specific standards such as performance measurement, clinical information management, and program management); and 3) Measurement of clinical outcomes. ${ }^{4}$ In relation to stroke performance measures, a set of ischemic stroke harmonized measures was developed and included but was not limited to deep venous thrombosis prophylaxis, antithrombotic therapy at discharge, anticoagulation therapy at discharge if the patient had atrial fibrillation, dysphagia screening, stroke education, smoking cessation advice/counseling, and assessment for rehabilitation. ${ }^{4}$ Furthermore, a subset of these stroke performance measures were included for hemorrhagic stroke patients (e.g., deep venous thrombosis prophylaxis, dysphagia screening, stroke education, etc.). It was at the discretion of the local primary stroke center to determine quality improvement plans and means to measure clinical outcomes. GWTG-S became a popular database tool to record and track performance measures.

In 2011, the BAC group revised and updated recommendations for establishment of primary stroke centers. ${ }^{85}$ Based on literature review and local experience, the following areas were highlighted in the revised, updated statement: 1) Importance of acute stroke teams; 2) Importance of stroke units with telemetry monitoring; 3) Utilization of magnetic resonance imaging and diffusion-weighted magnetic resonance imaging sequences; 4) Assessment of the cerebral vasculature by magnetic resonance angiography or computed tomographic angiography; 5)
Cardiac imaging to assess stroke etiology; 6) Early deployment of rehabilitation therapy; and 7) Independent local site certification that includes a site visit and disease performance measures.

Comprehensive Stroke Centers. In 2005, the BAC published a consensus statement about recommendations for comprehensive stroke centers. ${ }^{81}$ The recommendations emphasized service needs to deliver specialized care and included the following key components: 1) Specialized personnel (e.g., vascular neurology, vascular neurosurgery, critical care medicine, rehabilitative medicine, staff stroke nurses, and diagnostic radiology/neuroradiology); 2) Diagnostic techniques (e.g., magnetic resonance imaging with diffusion, computed tomographic angiography, conventional cerebral angiography, transesophageal echocardiography, and transcranial Doppler); 3) Availability of surgical and interventional therapies (e.g., carotid endarterectomy, endovascular ablation, ventriculostomy, intra-arterial reperfusion, and brain hematoma evacuation); 4) Infrastructure (e.g., stroke unit, intensive care unit, operating suite and interventional services coverage 24-hours/day, 7-days/week); and 5) Educational/Research Programs (e.g., community and professional education, and patient education). ${ }^{81}$

In September 2012, TJC launched an advanced certification program for Comprehensive Stroke Centers. ${ }^{86}$ The new level of certification recognizes the substantial resources needed to establish and manage complex stroke and cerebrovascular cases. The certification requires centers to meet Disease-Specific Care requirements including but not limited to the following criteria: the program is in the US and has TJC accreditation; uses standard methods to deliver clinical care and uses performance measures over time; and cares for a minimum number of patients. A summary of eligibility requirements, in synch with the BAC recommendations, ${ }^{81}$ is listed in Table $3 .{ }^{86}$ The first comprehensive stroke center applicants were reviewed in 2012 and approval certifications are being issued. For more information about the application process or application for a comprehensive stroke center the reader is referred to the following web sites:

http://www.jointcommission.org/certification/advanced_

Table 3. The Joint Commission Eligibility Requirements for Comprehensive Stroke Centers ${ }^{86}$

1. Meets Disease-Specific Care requirements

2. Volumes: 20 or more patients/year with subarachnoid hemorrhage, 15 or more endovascular ablations or aneurysmal clippings/year, and intravenous rtPA administration to at least 25 eligible acute ischemic stroke patients/year or over a 2-year period

3. Advanced Imaging: carotid duplex ultrasound, conventional cerebral angiography available on-site 24 hours/day, 7 days/week, computed tomographic angiography available on-site 24 hours/day, 7 days/week, extracranial ultrasonography, MR angiography-MRA available on-site 24 hours/day, 7 days/week, MRI, including diffusion weighted MRl available on-site 24 hours/day, 7 days/week, Transcranial Doppler, Transesophageal Echocardiography and Transthoracic Echocardiography

4. After hospital care coordination for stroke patients

5. Dedicated neurologic intensive care unit (ICU) beds for complex stroke cases

6. Peer review mechanism

7. Participation in IRB-approved, patient-centered stroke research

8. Collect standard performance measures for primary stroke centers and comprehensive stroke center performance measures, when available 
certification_comprehensive_stroke_centers.aspx and dscinfo@jointcommission.org

\section{Conclusion}

Stroke care has substantially evolved during the past several decades. The results of clinical trials of acute stroke care, prevention and rehabilitation have led to new evidence-based options for care of stroke patients. One of the major advancements in stroke is organization of care which has and is being transformed by primary and comprehensive stroke centers. The latter approaches promise to provide better outcomes and cost-effectiveness ones.

\section{References}

1. Barnett HJM, Buchan AM. The imperative to develop dedicated stroke centers. JAMA 2000;283:1325-1326.

2. Gorelick PB. An integrated approach to stroke prevention. In: Chalmers J, MacMahon S, Brass LM, Chapman N, Gorelick PB, Neal B (eds.): Clinician's Manual on Blood Pressure and Stroke Prevention, 3rd Edition. London: Science Press, 2002; 55-65.

3. Gorelick PB. Assessment of stent retrievers in acute ischemic stroke. Lancet 2012;380;1208-1210.

4. Fedder W. National and international quality initiatives to improve stroke care. Neurol Clin 2008;26:1191-1207.

5. Ruland S, Gorelick PB, Schneck M, Kim D, Moore CG, Leurgans S. Acute stroke care in Illinois. A statewide assessment of diagnostic and treatment capabilities. Stroke 2002;33:13341340.

6. Goldstein LB, Hey LA, Laney R. North Carolina stroke prevention and treatment facilities survey: statewide availability of programs and services. Stroke 2000;31:66-70.

7. Goldstein LB. Statewide hospital-based stroke services in North Carolina. Changes over 10 years. Stroke 2010;41:778-783.

8. Acker JE, Pancioli AM, Crocco TJ, Eckstein MK, Jauch EC, Larrabee $\mathrm{H}$, et al. Implementation strategies for emergency medical services within stroke systems of care. A policy statement from the American Heart Association/American Stroke Association Expert Panel on Emergency Medical Services Systems and the Stroke Council. Stroke 2007;116:3097-3115.

9. Marler JR, Winters Jones P, Emr M (eds.): Rapid Identification and Treatment of Acute Stroke. Proceedings of a national symposium sponsored by the NINDS, 12-13 December, 1996. Bethesda, MD: NIH, 1996.

10. National Stroke Association Stroke Center Network. http:// www.stroke.org/site/PageServer?pagename=SCN (accessed
December 25, 2012).

11. Brain Attack Coalition. www.BrainAttackCoalition.org (accessed December 25, 2012).

12. Leys D, Ringelstein EB, Kaste M, Hacke W, for the Executive Committee of the European Stroke Initiative. Facilities available in European hospitals treating stroke patients. Stroke 2007; 38:2985-2991.

13. Gordon DL. The Mississippi Stroke Education Consortium: A state-based template to promote stroke awareness, prevention and emergency treatment. Neuroepidemiology 2000;19:1-12.

14. Song S, Saver J. Growth of regional acute stroke systems of care in the United States in the first decade of the 21st century. Stroke 2012;43:1975-1978.

15. Fedder W. The Joint Commission's Initiative's to Improve Stroke Care and What It Means for Acute Stroke Care and Prevention. In: Aiyagari V, Gorelick PB (eds.): Hypertension and Stroke. Pathophysiology and Management. New York: Humana Press, 2011;259-268.

16. Reeves MJ, Fonarow GC, Smith EE, Pan W, Olson DW, Hernandez AF, et al. Representativeness of the Get With The Guidelines-Stroke Registry. Comparison of patient and hospital characteristics among Medicare beneficiaries hospitalized with ischemic stroke. Stroke 2012;43:44-49.

17. Parker C, Schwamm LH, Fonarow GC, Smith EE, Reeves MJ. Stroke quality metrics. Systematic reviews of the relationships to patient-centered outcomes and impact of public reporting. Stroke 2012;43:155-162.

18. Abileira S, Ribera A, Permanyer-Miralda G, Tresserras R, Gallofre $\mathrm{M}$. Noncompliance with certain quality indicators is associated with risk-adjusted mortality after stroke. Stroke 2012;43: 1094-1100.

19. Foranow GC, Pan W, Saver JL, Smith EE, Reeves MJ, Broderick JP, et al. Comparison of 30-day mortality models for profiling hospital performance in acute ischemic stroke with vs without adjustment for stroke severity. JAMA 2012;308:257-264.

20. Burgin WE, Staub MS, Chan W, Wein TH, Felberg RA, Grotta $\mathrm{JC}$, et al. Acute stroke care in non-urban emergency departments. Neurology 2001;57:2006-2012.

21. Leira EC, Hess DC, Torner JC, Adams HP. Rural-urban differences in acute stroke management practices. A modifiable disparity. Arch Neurol 2008;65:887-891.

22. Joubert J, Prentice LF, Moulin T, Liaw S-T, Joubert LB, Preux $\mathrm{P}-\mathrm{M}$, et al. Stroke in rural areas and small communities. Stroke 2008;39:1920-1928.

23. Kleindorfer D, Khoury J, Broderick JP, Rademacher E, Woo D, Flaherty ML, et al. Temporal trends in public awareness of stroke. Warning signs, risk factors, and treatment. Stroke 2009;40:25022506. 
24. Howard VJ, Lackland DT, Lichtman JH, McClure LA, Howard G, Wagner L, et al. Care seeking after stroke symptoms. Ann Neurol 2008;63:466-472.

25. Qureshi AI, Suri FK, Kirmani JF, Divani AA. The relative impact of inadequate primary and secondary prevention on cardiovascular mortality in the United States. Stroke 2004;35:23462350.

26. Jencks SF, Williams MV, Coleman EA. Rehospitalizations among patients in the Medicare fee-for-service program. $N$ Engl J Med 2009;360:1418-1428.

27. Ross JS, Halm EA, Bravatta DM. Use of secondary prevention services. Are there disparities in care? Stroke 2009; 40:18111819.

28. Cameron JI, Tsoi C, Marsella A. Optimizing stroke systems of care by enhancing transitions across care environments. Stroke 2008;39:2637-2643.

29. Touze E, Coste J, Voicu M, Kansao J, Masmoudi R, Doumenc $B$, et al. Importance of in-hospital initiation of therapies and inertia in secondary stroke prevention. Implementation of Prevention After a Cerebrovascular event (IMPACT) study. Stroke 2008;39:1834-1843.

30. Govan L, Weir CJ, Langhorne P, for the Stroke Unit Trialists' Collaboration. Organized inpatient (stroke unit) care for stroke. Stroke 2008;39:2402-2403.

31. Kidwell CS, Shephard T, Tonn S, Lawyer B, Murdock M, Koroshetz W, et al. Establishment of primary stroke centers. A survey of physician attitudes and hospital resources. Neurology 2003;60:1452-1456.

32. Saposnik G, Fang J, O’Donnell M, Hachinski V, Kapral MK, Hill MD, et al. Escalating levels of access to in-hospital care and stroke mortality. Stroke 2008;39:2522-2530.

33. Xian Y, Holloway RG, Chan PS, Noyes K, Shah MN, Ting HH, et al. Association between stroke center hospitalization for acute ischemic stroke and mortality. JAMA 2011;305:373-380.

34. Holloway RG, Tuttle D, Baird T, Skelton WK. The safety of hospital stroke care. Neurology 2007;68:550-555.

35. Indredavik B, Bakke F, Solberg R, Rokseth R, Haaheim LL, Holme I. Benefit of a stroke unit: a randomized controlled trial. Stroke 1991;22:1026-1031.

36. Govan L, Langnorne P, Weir CJ, for the Stroke Unit Trialists Collaboration. Does the Prevention of Complications Explain the Survival Benefit of Organized Inpatient (Stroke Unit) Care? Further Analysis of a Systematic Review. Stroke 2007;38:25362540.

37. Gropen TI, Gagliano PJ, Blake CA, Sacco RL, Kwiatkowski T, Richmond NJ, et al. Quality improvement in acute stroke. The New York State Stroke Center Designation Project. Neurology 2006;67:88-93.
38. Demaerschalk BM, Bobrow BJ, Paulsen M, Phoenix Operation Stroke Executive Committee on behalf of the Phoenix Meteropolitan Matrix of Primary Stroke Centers. Development of a Metropolitan Matrix of Primary Stroke Centers: The Phoenix Experience. Stroke 2008;39:1246-1253.

39. Saposnik G, Baibergenova A, O’Donnell M, Hill MD, Kapral MK, Hachinski V, et al. Hospital volume and stroke outcome. Neurology 2007;69:1142-1151.

40. Lin HC, Zirasagar S, Chen CH, Lin CC, Lee HC. Association between physician volume and hospitalization costs for patients with stroke in Taiwan. A nationwide population-based study. Stroke 2007;38:1565-1569.

41. Zhu H, Newcommon NN, Cooper ME, Green TL, Seal B, Klein G, et al. Impact of a stroke unit on length of hospital stay and in-hospital case fatality. Stroke 2009;40:18-23.

42. Saka O, Serra V, Samyshkin Y, McGuire A, Wolfe CCDA. Costeffectiveness of stroke unit care followed by early supported discharge. Stroke 2009;40:24-29.

43. Gattellari M, Worthington J, Jalaludin B, Mohsin M. Stroke unit care in a real-life setting. Can results from randomized controlled trials be translated into every-day clinical practice? An observational study of hospital data in a large Australian population. Stroke 2009;40:10-17.

44. Caplan LR. Stroke is best managed by neurologists. Stroke 2003; 34:2763.

45. Lees KR. Stroke is best managed by a neurologist: battle of the titans. Stroke 2003;34:2764-2765.

46. Donnan GA, Davis SM. Neurologist, internist, or strokologist? Stroke 2003;34:2765.

47. Evans A, Harraf F, Donaldson N, Kalra L. Randomized controlled study of stroke unit care versus stroke team care in different stroke subtypes. Stroke 2002;33:449-455.

48. Smith EE, Hassan KA, Fang J, Selchen D, Kapral MK, Saposnik G, on behalf of the investigators of the Registry of the Canadian Stroke Network (RCSN) for the Stroke Outcome Research Canada (SORCan) Working Group. Do all ischemic stroke subtypes benefit from organized inpatient stroke care? Neurology 2010;75:456-462.

49. Saposnik G, Kapral MK, Coutts SB, Fang J, Demchuk AM, Hill MD, on behalf of the investigators of the Registry of the Canadian Stroke Network (RCSN) for the Stroke Outcome Research Canada (SORCan) Working Group. Do All Age Groups Benefit From Organized Inpatient Stroke Care? Stroke 2009;40:3321-3327.

50. Reeves MJ, Parker C, Fonarow GC, Smith EE, Schwamm LH. Development of stroke performance measures. Definitions, methods and current measures. Stroke 2010;41:1537-1578.

51. Reeves MJ, Gargano J, Maier KS, Broderick JP, Frankel M, La- 
Bresh KA, et al. Patient-level and hospital-level determinants of the quality of acute stroke care. A multilevel modeling approach. Stroke 2010;41:2924-2931.

52. Douglas VC, Tong DC, Gillum LA, Zhao S, Brass LM, Dostal J, et al. Do the Brain Attack Coalition's criteria for stroke centers improve care for ischemic stroke? Neurology 2005;64: 422427.

53. California Acute Stroke Pilot Registry (CASPR) Investigators. The impact of standardized stroke orders on adherence to best practices. Neurology 2005;65:360-365.

54. Johnston SC, Sidney S, Hills NK, Grosvenor D, Klingman JG, Bernstein A, et al. Standardized discharge orders after stroke. Results of the Quality Improvement in Stroke Prevention (QUISP) cluster randomized trial. Ann Neurol 2010;67:579-589.

55. Lakshminarayan K, Borbas C, McLaughlin B, Morris NE, Vazquez G, Luepker RV, et al. A cluster randomized trial to improve stroke care in hospitals. Neurology 2010;74:1634-1642.

56. Wolfe CDA, Redfern J, Rudd AG, Grieve AP, Heushmann PU, McKevitt C. Cluster randomized controlled trial of a patient and general practitioner intervention to improve the management of multiple risk factors after stroke. Stop Stroke. Stroke 2010;41:2470-2476.

57. Hsieh FI, Lien LM, Chen ST, Bai CH, Sun MC, Tseng HP, et al. Get With The Guidelines-Stroke performance indicators: surveillance of stroke care in the Taiwan Stroke Registry. Get With The Guidelines-Stroke Taiwan. Circulation 2010;122: 1116-1123.

58. Smith EE, Liang L, Hernandez A, Reeves MJ, Cannon CP, Fonarow GC, et al. Influence of stroke subtype on quality of care In the Get WithThe Guidelines-Stroke Program. Neurology 2009;73:709-716.

59. Schwamm LH, Fonarow GC, Reeves MJ, Pan W, Frankel MR, Smith EE, et al. Get With The Guidelines-Stroke is associated with sustained improvement in care for patients hospitalized with acute stroke or transient ischemic attack. Circulation 2009; 119:107-115.

60. Reeves MJ, Fonarow GC, Zhao X, Smith EE, Schwamm LH, on behalf of the GWTG-S Steering Committee \& Investigators. Quality of care in women with ischemic stroke in the GWTG Program. Stroke 2009;40:1127-1133.

61. Schwamm LH, Reeves MJ, Pan W, Smith EE, Frankel JR, Olson $\mathrm{D}$, et al. Race/ethnicity, quality of care, and outcomes in ischemic stroke. Circulation 2010;121:1492-1501.

62. Bushnell CD, Zimmer LO, Pan W, Olson DM, Zhao X, Meteleva T, et al. Persistence with stroke prevention medications 3 months after hospitalization. Arch Neurol 2010;67:14561463.

63. Smith EE, Pan W, Olson DW, Reeves MJ, Ovbiagele B, Peter- son ED, et al. Frequency and determinants of lipid testing in ischemic stroke and transient ischemic attack. Findings from Get With The Guidelines-Stroke. Stroke 2010;41:232-238.

64. Allen NB, Kaltenbach L, Goldstein LB, Olson DW M, Smith EE, Peterson ED, et al. Regional variation in recommended treatments for ischemic stroke and TIA. Get With The Guidelines-Stroke 2003-2010. Stroke 2012;43:1858-1864.

65. Albright KC, Branas CC, Meyer BC, Matherne-Meyer DE, Zivin JA, Lyden PD, et al. Acute cerebrovascular care in emergency stroke systems. Arch Neurol 2010;67:1210-1218.

66. Silva GS, Farrell S, Shandra E, Viswanathan A, Schwamm LH. The status of telestroke in the United States. A survey of currently active stroke telemedicine programs. Stroke 2012;43: 2078-2085.

67. Schwamm LH, Audebert HJ, Amarenco P, Chumbler NR, Frankel MR, George MG, et al. Recommendations for the implementation of telemedicine within stroke systems of care. A policy statement from the American Heart Associaiton. Stroke 2009;40:2635-2660.

68. Schwamm LH, Holloway RG, Amarenco P, Audebert HJ, Bakas T, Chumbler NR, et al. A review of the evidence for the use of telemedicine within stroke systems of care. A scientific statement from the American Heart Association/American Stroke Association. Stroke 2009;40:2616-2634.

69. Demaerschalk BM, Miley ML, Kiernan TE, Bobrow BJ, Corday DA, Wellik KE, et al. Stroke telemedicine. Mayo Clin Proc 2009;84:53-64.

70. Hess DC, Wang S, Gross H, Nichols FT, Hall CE, Adams RJ. Telestroke: extending stroke expertise into underserved areas. Lancet Neurol 2006;5:275-278.

71. Zaidi SF, Jumma MA, Urra XN, Hammer M, Massaro L, Reddy $\mathrm{V}$, et al. Telestroke-guided intravenous tissue-type plasminogen activator treatment achieves a similar clinical outcome as thrombolysis at a comprehensive stroke center. Stroke 2011;42: 3291-3293.

72. Sairanen T, Soinila S, Nikkanen M, Rantanen K, Mustanoja S, Farkkila M, et al. Two years of Finnish telestroke. Thrombolysis at spokes equal to that at the hub. Stroke 2011;76:1145-1152.

73. Schwab S, Vatankhah B, Kukla C, Hauchwitz M, Bogdahn U, Furst A, et al. Long-term outcome after thrombolysis in telemedical stroke care. Neurology 2007;69:898-903.

74. Levine SR, McConnochie KM. Telemedicine for acute stroke. When virtual is as good as reality. Neurology 2007;69:819-820.

75. Demaerschalk BM, Hwang HM, Leung G. US cost burden of ischemic stroke: a systematic literature review. Am J Manag Care 2010; 16:525-533.

76. Demaerschalk BM, Hwang HM, Leung G. Cost analysis review of stroke centers, telestroke, and rt-PA. Am J Manag Care 
2010;16:537-544.

77. Nelson RE, Saltzman GM, Skalabrin EJ, Demaerschalk BM, Majersik JJ. The cost-effectiveness of telestroke in the treatment of acute ischemic stroke. Neurology 2011;77:1590-1598.

78. Rudolph SH, Levine SR. Telestroke, QALYs, and current health care policy. The Heisenberg uncertainty principle. Neurology 2011;77:1584-1585.

79. Alberts MJ, Hademenos G, Latchaw RE, Jagoda A, Marler J, Mayberg MR, et al. Recommendations for the establishment of primary stroke centers. JAMA 2000;283:3102-3109.

80. Gorelick PB. Acute ischemic stroke and transient ischemic attack: a costly business and strategy to reduce costs and length of stay: the time zero plan. J Stroke Cerebrovasc Dis 1995;5:1-5.

81. Alberts MJ, Latchaw RE, Selman WR, Shephard T, Hadley $\mathrm{MN}$, Brass LM, et al Recommendations for comprehensive stroke centers. A consensus statement from the Brain Attack Coalition. Stroke 2005;36:1597-1618.

82. McKinney JS, Deng Y, Kasner SE, Kostis JB, for the Myocardial Infarction Data Acquisition System (MIDAS 15) Study Group.
Comprehensive Stroke Centers Overcome the Weekend Versus Weekday Gap in Stroke Treatment and Mortality. Stroke 2011;42:2403-2409.

83. Mereoja A, Roine RO, Kaste M, Linna M, Roine S, Juntunen $\mathrm{M}$, et al. Effectiveness of primary and comprehensive stroke centers. PERFECT Stroke: a nationwide observational study from Finland. Stroke 2010;41:1102-1107.

84. Sanyal R, Barrick J, Bhalla A, Cassidy T, Collas D, Cloud G, et al. The 2010 British Association of Stroke Physicians Survey of interventional treatments for stroke in the United Kingdom. International Journal of Stroke (Jan 2013; in press)

85. Alberts MJ, Latchaw RE, Jagoda A, Wechsler LR, Crocco T, George MG, et al. Revised and updated recommendations for the establishment of primary stroke centers. A summary statement from the Brain Attack Coalition. Stroke 2011;42:26512665.

86. http://www.jointcommission.org/certification/advanced certification_comprehensive_stroke_centers.aspx (accessed December 28, 2012). 